\title{
Effect of Extensive and Limited Plastic Deformation on Recrystallized Microstructure of Oxide Dispersion Strengthened Fe-Cr-Al Alloy
}

\author{
Carlos Capdevila ${ }^{1, *(\mathbb{D})}$, Rosalia Rementeria ${ }^{1,2}{ }^{\mathbb{D}}$, Maria M. Aranda ${ }^{1}$, Javier Vivas ${ }^{1}$, Jesus Chao ${ }^{1}$ \\ and Vicente Amigó ${ }^{3}$ (D) \\ 1 Materalia Group, Centro Nacional de Investigaciones Metalúrgicas (CENIM), Consejo Superior de \\ Investigaciones Científicas (CSIC), Avda. Gregorio del Amo, 8. E-28040 Madrid, Spain; \\ rosalia.rementeria@cenim.csic.es (R.R.); mariamartinaranda@gmail.com (M.M.A.); \\ jvm@cenim.csic.es (J.V.); jchao@cenim.csic.es (J.C.) \\ 2 SLab, ArcelorMittal Global R\&D Asturias, calle Marineros 4, 33490 Avilés, Asturias, Spain \\ 3 Instituto de Tecnología de Materiales de la Universidad Politécnica de Valencia, Camino de Vera, s/n. \\ 46022 Valencia, Spain; vamigo@mcm.upv.es \\ * Correspondence: ccm@cenim.csic.es; Tel.: +34-91-5538900; Fax: +34-91-5347425
}

Received: 6 November 2018; Accepted: 5 December 2018; Published: 11 December 2018

\begin{abstract}
Ferritic oxide dispersion-strengthened alloys (ODS) are manufactured using a mechanical alloying process. The development of a coarse-grained microstructure during recrystallization has been detected and discussed by several authors, but the mechanism of grain growth remains uncertain. Recent work has emphasized the large influence of non-uniformities on the development of the recrystallized microstructure. The purpose of the present work is to study the effect of both slight heterogeneous plastic strains and strong directional deformation on recrystallization of a ferritic Fe-base ODS alloy.
\end{abstract}

Keywords: cold deformation; oxide dispersion strengthened alloy; compression test; directional recrystallization; extended recovery

\section{Introduction}

The first ferritic oxide dispersion-strengthened (ODS) alloys were developed by the Belgian Nuclear Research Center (SCK CEN) in the 1960s in the frame of sodium-cooled fast breeders [1] because of their higher thermal conductivity, lower thermal expansion, and lower tendency to He-embrittlement in comparison to austenitic alloys. Since then, many applications have been foreseen for this type of advanced material, mostly in circumstances where a combination of creep strength and oxidation resistance is of paramount importance. For example, a new generation of $\mathrm{Fe}-\mathrm{Cr}-\mathrm{Al}$ ferritic steels is being considered as structural material for new GEN-IV fission reactors [2]. As the ferritic state makes the alloy resistant to radiation-induced swelling, and the aluminum content boosts the formation of a protective alumina layer against liquid metal embrittlement, some of the alloys of this family were intended for use in the manufacture of tubes for new-generation nuclear reactors cooled by liquid sodium at about $700{ }^{\circ} \mathrm{C}[3]$.

Nevertheless, Fe-Cr-Al ferritic steels tend to undergo a marked loss in creep strength at temperatures in excess of $600{ }^{\circ} \mathrm{C}$; the ODS Fe-Cr-Al alloys discussed here can, in principle, be used at much higher temperatures, perhaps as high as $1100^{\circ} \mathrm{C}$ [4]. The stability of the microstructure at elevated temperatures (above $1000^{\circ} \mathrm{C}$ ) is achieved by the uniform dispersion of nanosized oxides in the microstructure. The most common means of introducing unmixable components such as ceramic oxide particles in a metallic matrix is by the mechanical alloying processing route, using high-energy 
milling to deform mixtures of elemental or alloyed metal powders [1,5-7]. The effect of milling is the conversion of the heterogeneous mixture of powders into one in which each particle is a solid solution with an extremely fine grain structure.

Immediately after the mechanical alloying process, the powders have a grain size that can be as fine as 1-2 $\mathrm{nm}$, locally [8]. This is a consequence of the extent of deformation during mechanical alloying, with true strains on the order of 9, equivalent to stretching a unit length by a factor of 8000 . In addition to that enormous stored energy, however, the recrystallization occurs at exceptionally high homologous temperatures, of the order of 0.9 of the melting temperature $\left(T_{M}\right)$. This contrasts with ordinary cold-deformed metals, which recrystallize readily at about $0.6 T_{\mathrm{M}}$. The reason for such intriguing behavior remains unclear and is the motivation for this work.

Some authors have speculated [9] that recrystallization occurs when the grain boundaries overcome solute drag and the mobility rises suddenly at high temperatures. This is inconsistent with some experimental evidence that demonstrates that the recrystallization temperature can be reduced by many hundreds of Kelvin by a slight additional inhomogeneous deformation [10,11]. Conversely, other authors have suggested that the fine particles of yttrium oxide may offer hard pinning for moving boundaries during recrystallization, but this does not explain why the limiting grain size following recrystallization is enormous. In any case, recrystallization is found to be insensitive to the overall pinning force [12].

In summary, there is a need to explain why recrystallization temperature is so high, and why changes in processing, which induce relatively slight deformations in the ODS material, can produce enormous changes in the subsequent recrystallization behavior [13]. Therefore, the role played by plastic strains inferred during manufacturing in tuning the microstructure of these materials is of paramount importance to improving the in-service response of the material. Specifically, this paper deals with the influence that different levels of plastic deformation and their direction in the consolidated state have on the microstructure of ferritic ODS alloys. This paper contemplates two different parts. First, a review of the mechanism of recrystallization reported for this type of material, and secondly, new results of the impact of plastic deformation on the final grain structure achieved, which makes it possible to generate a variety of microstructures, in line with the needs of the foreseen function.

\section{Material and Experimental Procedure}

The Fe-base ODS PM2000 (Fe-20Cr-6Al-0.5Ti-0.5 $\mathrm{Y}_{2} \mathrm{O}_{3}$ ), supplied by PLANSEE GmbH, is manufactured by mechanical alloying. Powders with a grain size of about $70 \mathrm{~nm}$ were consolidated by hot isostatic pressing and subsequently extruded as vacuum-sealed cans at about $1000{ }^{\circ} \mathrm{C}$ to form a tube with a wall thickness of $7 \mathrm{~mm}$.

\subsection{Initial Microstructure}

The microstructure of as-extruded PM2000 consists of elongated grains along the extrusion direction with a high grain aspect ratio $(\mathrm{GAR}=4), 3-4 \mu \mathrm{m}$ in length, and $0.5 \mu \mathrm{m}$ diameter, as reported elsewhere [14,15]. A relatively low dislocation density was observed [16]. It has been reported previously $[10,13,14]$ that it has a higher frequency of low-angle grain boundaries (LAGB), i.e., with misorientation of between $4^{\circ}$ and $15^{\circ}$, than a random distribution; meanwhile the frequency of high-angle grain boundaries (HAGB), i.e., with misorientation larger than $15^{\circ}$, is lower than random.

This particular distribution of grain boundaries and the submicron grain structure observed in as-extruded PM2000 is consistent with the assumption that the stored energy in ODS ferritic steels is primarily in the form of grain surfaces, while the excess of energy stored in conventional ferritic steels is in the form of dislocations.

The existence of a preferential orientation of $<110>$ along the extrusion direction was also reported [13]. The corresponding $\phi_{2}=45^{\circ}$ section of the Euler space, using Bunge's angular system, confirms a strong incomplete $\alpha$-fiber texture $(<110>\|$ ED and $<100>\| N D$, where ED stands for the 
extrusion direction and ND for the normal direction) with a dominating rotated cube $\{001\}<110>$ and a secondary $\{111\}<1 \overline{1} 0>$ component. This texture is typical of body-centered cubic materials deformed by either extrusion or rolling.

\subsection{Determination of Mechanical Properties}

The extensive and directional plastic deformation was induced under uniaxial compression tests carried out in two sets of $6.7 \times 6.7 \mathrm{~mm}^{2}$ cubic samples machined from the as-extruded tube. One set is deformed parallel to extrusion direction (L-samples) and the other set is deformed normal to extrusion direction (N-samples). All the compression tests were carried out at room temperature in a MicroTest $100 \mathrm{kN}$ testing machine (Microtest S.A., Madrid, Spain).

The limited and homogeneous plastic deformation was carried out on prismatic samples $60 \mathrm{~mm}$ in length and $20 \times 7 \mathrm{~mm}^{2}$ sections machined from the as-extruded tube. Spherical indentations (Brinell tests) at the inner wall were performed with a spherical indenter $10 \mathrm{~mm}$ in diameter. Loads ranging from 4.9 to $49 \mathrm{kN}$ were applied. Figure 1 illustrates the scheme of the positions of the samples in the wall thickness for the experimental setups of compression and Brinell tests.

(a)

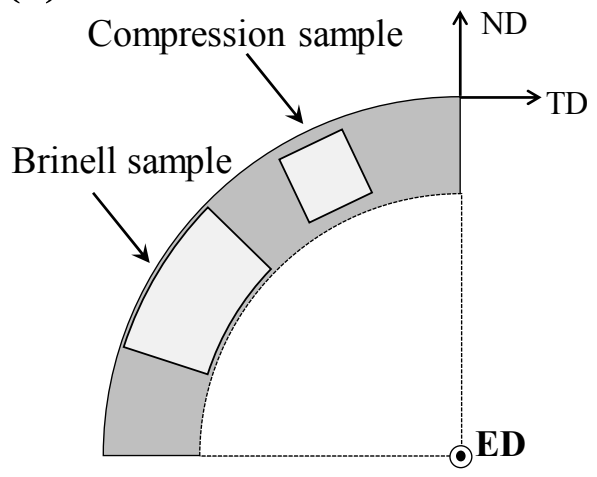

(b)

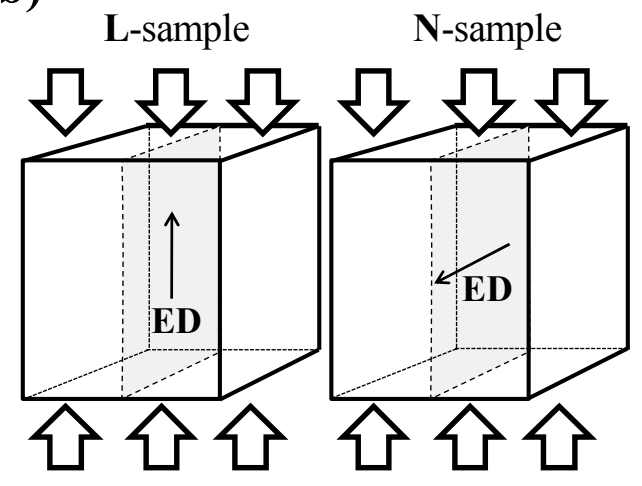

Figure 1. (a) Position of machined simples in the wall thickness of PM2000 tube, and reference system for further EBSD measurements; (b) relative position of deformation direction to extrusion direction (ED) in compression tests.

Recrystallization heat treatments were carried out in a Therm Concept HT0417 furnace (Steriltech S.L., Madrid, Spain). The furnace has $\mathrm{MoSi}_{2}$ heating elements that can reach $1700{ }^{\circ} \mathrm{C}$ with a heating ramp of $10 \mathrm{~h}$ from room temperature to recrystallization temperatures ranging from 1100 to $1350{ }^{\circ} \mathrm{C}$. The sample is held at recrystallization temperature for one hour and cooled down over $5 \mathrm{~h}$ to $600^{\circ} \mathrm{C}$, and then quenched in water.

\subsection{Determination of Microtexture}

Microtexture analysis of specimens was performed by the Electron Backscattering Diffraction (EBSD) technique. The EBSD patterns were generated at an acceleration voltage of $20 \mathrm{kV}$ and collected using a CRYSTAL detector of Oxford Instruments (Oxford, UK) mounted in a FEG-SEM JEOL JSM6500. The indexation of the Kikuchi lines and the determination of the orientations were done with the software CHANNEL 5 developed by HKL Technologies (Oxford, UK). The reference system for the EBSD analysis is indicated in Figure 1. In this sense, the extrusion (or rolling) direction is parallel to $\mathrm{X} 0$-axis of the microscope chamber (ED or RD I IX0), the tangential direction is parallel to $\mathrm{Y} 0$-axis (TD $\mid$ | Y0), and the normal direction parallel to Z0-axis (ND $\mid \mathrm{Z0}$ ). 


\section{Results and Discussion}

\subsection{Recrystallization Mechanism in ODS FeCrAl Alloys}

An extensive and detailed explanation of the recrystallization process in ODS Fe-Cr-Al alloy, i.e., microstructural evolution and recrystallization mechanism, was reported by the authors previously [17]. For the shake of understanding the new concepts reported in this paper, we summarize in this section the most relevant conclusions achieved on the recrystallization process in ODS FeCrAl alloys. It is the intention of the authors to facilitate the reader in following the changes that heterogeneous deformation and severe deformation have on recrystallization, as will be described in further sections.

Several works in recent years have dealt with the apparent paradox of high recrystallization temperatures for mechanically alloyed metals [18,19]. Ferritic ODS steels contain more stored energy than any conventional cold-rolled ferritic steels that recrystallize at lower temperatures; recrystallization is normally accelerated as the stored energy increases.

The nucleation of recrystallization begins by the bowing of a grain boundary, which in a conventionally processed ferritic steel is normally straightforward, because the size of the boundary perturbation is small when compared to the grain size. Some authors argue that in the case of the nanometer-sized grain structures obtained after MA processing, the boundary junctions themselves act as severe pinning lines, restricting bowing [20,21]. This leads to an enormous activation energy for the nucleation of recrystallization, ten times higher than the activation energy for self-diffusion [20,22]. However, the activation energy is reduced if a few grains happen to be larger, mainly caused by any non-uniformity introduced into the microstructure, for example by inhomogeneous deformation [23-25]. This model suggests that the individual grains cannot be considered to be topologically independent when the grain size becomes small. It is predicted correctly that the recrystallization temperature should decrease if a low-temperature heat treatment, which leads to uniform grain coarsening, is applied.

This model is consistent with the experimental evidence of high recrystallization temperature and also, as will be discussed in subsequent sections, the broad idea that anything that introduces heterogeneity into the microstructure will decrease the recrystallization temperature. However, this model does not deal with texture, and hence cannot explain the texture changes observed between the deformed microstructure and the one resulting after recrystallization.

The evolution of microstructure during recrystallization annealing at $1350{ }^{\circ} \mathrm{C}$ for different times of PM2000, as compared with the as-extruded condition, is shown in Figure 2. The comparison with the as-extruded microstructure (Figure 2a) reveals that no major changes in texture are produced after 6 min of annealing, but an incipient coarsening of the grain structure is detected (Figure 2b). Such coarsening is clearly observed after $15 \mathrm{~min}$ of annealing, as shown in Figure 2c. The grain size evolves from the submicron range to a few tens of microns in average diameter. In addition, a strengthening of the cube texture is also noticed. Finally, the recrystallization is complete after 25 min of annealing (Figure 2d). The resulting coarse grain structure presents an average grain size of $180 \mu \mathrm{m}$, and $\{112\}$ type grains. 

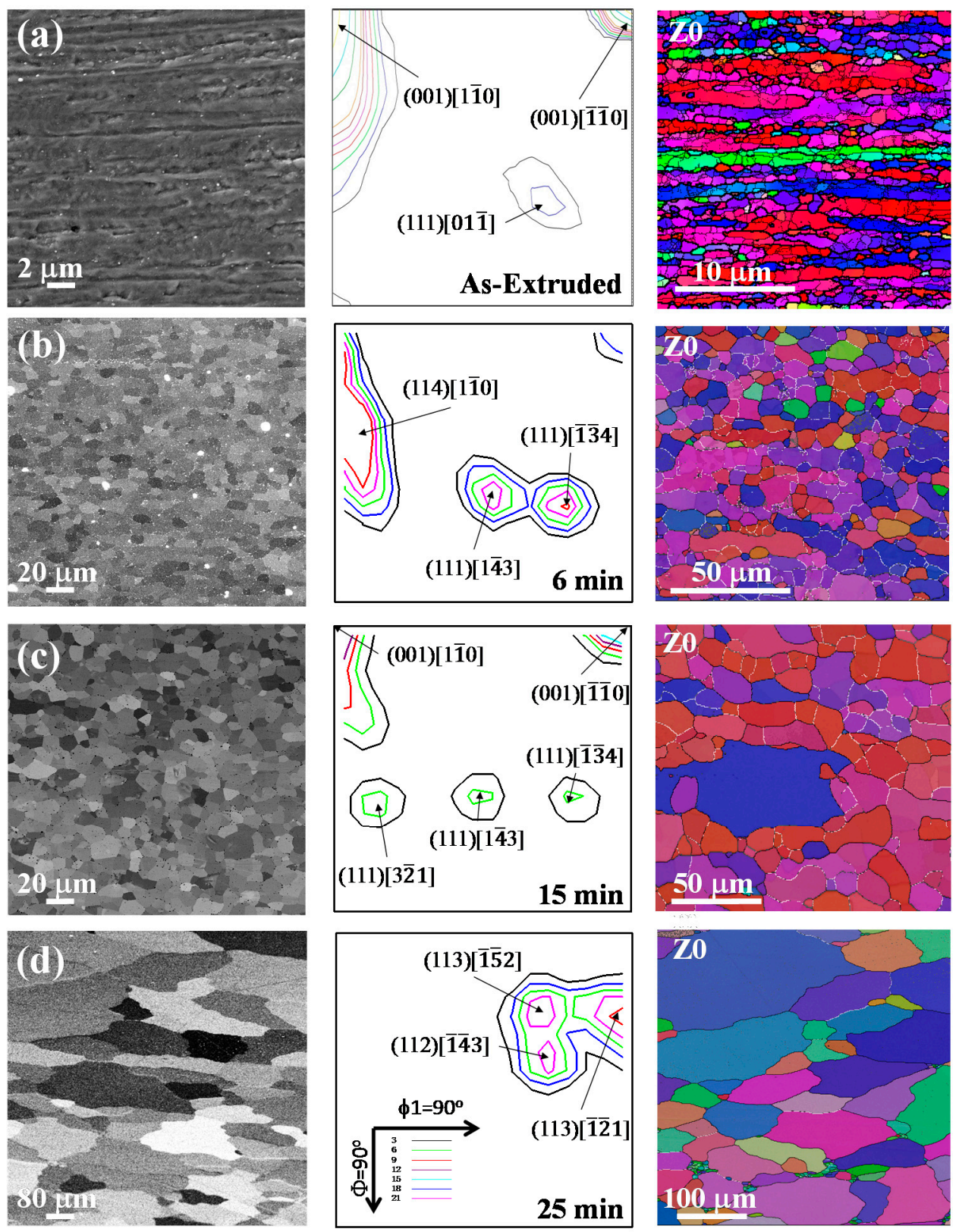

Figure 2. SEM image of longitudinal sample, $\phi_{2}=45^{\circ}$ section of ODF (Orientation Distribution Function), and EBSD map of recrystallization-annealed microstructure: (a) as-extruded; and after (b) $6 \mathrm{~min}$, (c) $15 \mathrm{~min}$, and (d) $25 \mathrm{~min}$. The black solid lines in EBSD maps represents the HAGB; meanwhile, the finer white solid lines represents the LAGBs. Please note that scale bars are different.

Figure 2 also illustrates the ODFs corresponding to the different recrystallization annealing times. It is observed that during the extended recovery process, the texture does not change $(<110\rangle \| R D)$, although subgrain rotation implies the strengthening of orientations with the lowest Taylor factor, i.e., $\{001\}<110>$. The particular processing route of PM2000 will modify the recrystallization process of this ODS ferritic steel as compared with a conventional processed steel beyond the fact of differences in stored energy. The recrystallization temperature of PM2000 was reported as $1330{ }^{\circ} \mathrm{C}$ [26], which corresponds to $0.9 \mathrm{~T}_{\mathrm{M}}$. The results reported by Dillamore [27] and Every and Hatherly [28] demonstrate a correlation between the Taylor M-value, a factor proportional to the amount of slip activity taking place in the different orientations, and the recrystallization temperature. It was concluded from their studies that strain heterogeneities occur more readily in grains of high $\mathrm{M}$-value such as $\gamma$-fiber grains than in the $\alpha$-fiber grains, which deform efficiently and cannot save energy by altering their strain 
state. Therefore, recrystallization of a hard $\alpha$-fiber texturized material such as PM2000 will require of higher temperature than conventionally processed ferritic steels.

From Figure 2, it might be concluded that sub-boundary movement (migration and coalescence) is prevalent, which implies the prevalence of deformation texture. As pointed out by Doherty et al. [29], if HAGBs do not move or become immobilized as they develop, then the recrystallization process is properly termed a recovery process. Therefore, the recrystallization process in PM2000 is, in fact, an extended recovery process $[17,30,31]$, although for the sake of simplicity we will denote it hereinafter as recrystallization.

Pimentel and co-workers [17] reported the evolution of misorientations in the microstructure during recrystallization annealing. Although an increase in the frequency of HAGBs during recrystallization to the detriment of LAGBs should be expected, this was not observed during the annealing of PM2000. Conversely, the frequency of LAGB increases. Therefore, the microstructure is mainly formed by oriented grains separated by HAGBs and sub-divided by LAGBs. Moreover, the matrix has some grains of other orientations (weak texture) that are not mostly divided by LAGBs.

The works of Chou and Bhadeshia $[11,32,33]$ revealed that an elevated density of LAGBs, as compared to HAGBs, in the as-extruded microstructure indicates that recrystallization is not likely to proceed by the grain boundary bowing mechanism described above. The results shown in Figure 2 for the boundary misorientation evolution are consistent with the subgrain rotation mechanism driven by dislocation glide as described by Lyttle et al. [34].

As pointed out by Pimentel et al. [17], a microstructure mainly formed by oriented grains separated by HAGBs and sub-divided by LAGBs such as the PM2000 might be subjected to a phenomenon known as "orientation pinning". First introduced by Juul Jensen [35], the concept of "orientation pinning" has been used to explain the dominance of grains with a preferred orientation relationship. This phenomenon is related to the experimental observation that LAGBs have low mobility and can be regarded as essentially sessile. In the case of PM2000, it might be argued that $\{110\}$ grains are "orientation pinned" because they encounter grains of similar orientation, thereby forming low-angle sessile boundaries. In this case, the sessile boundaries act as obstacles to the moving HAGBs and, consequently, will pin them in analogy to the well-known case of Zener-particle pinning.

As a matter of fact, the orientation pinning mechanism implies a decrease in the frequency of HAGBs between grains of the same orientation, which act as LAGBs in terms of movement. Then, there is a local decrease in the density of HAGBs; towards deformed areas with growing grain of the same or almost the same orientation, the segment becomes a LAGB. This is consistent with the results shown in Figure 2.

Nevertheless, preferential growth is then toward grains that are distinguished by a low probability of being pinned by sessile boundaries. The orientations of these grains eventually predominate in the recrystallization texture. In the particular case of PM2000, $\{112\}$ and $\{113\}$ grains maintain high-angle boundaries with the deformed $\{110\}$ matrix. Therefore, the recrystallized microstructure in PM2000 is predominantly formed by $\{112\}$ and $\{113\}$ grains. Hence, the migration rates of the weak texture component boundary can be higher than the strong texture component, as pointed out by Vandermeer and Juul Jensen [36].

\subsection{Role of Limited Non-Directional Plastic Deformation on Recrystallization}

As mentioned above, ferritic ODS alloys present a high stored energy after consolidation in the form of a sub-micron microstructure, e.g., the stored energy of MA957 is typically $1 \mathrm{~J} \cdot \mathrm{g}^{-1}$, which is much higher than in conventionally deformed metals [33]. An important observation by Alamo et al. [37] is that the recrystallization temperature dramatically decreases if the consolidated material is cold-deformed prior to annealing. This observation has been confirmed in the work carried out by Nutting [38] and Capdevila et al. [39] in different ODS steels, where it was observed that there is a decrease in the recrystallization temperature and an increase in the density of recrystallization nuclei as cold deformation increases. 
The dramatic effect that limited plastic deformation has on the recrystallized grain structure can be observed in Figure 3. This figure shows the microstructure following recrystallization at $1350{ }^{\circ} \mathrm{C}$ for $3 \mathrm{~h}$ after a Brinell test in as-extruded PM2000 tube (after [26,39]). Optical microscopy analysis revealed that the lower the deformation, the larger the grain size and the lower the number of recrystallized grains that appear in the microstructure. In the area affected by deformation, the recrystallized grain is equiaxed, but a few orders of magnitude smaller than the recrystallized grains in the non-deformed region (Figure $3 \mathrm{a}, \mathrm{b}$ ). It is evident the effect of the deformation magnitude on the recrystallization, since the bigger the indentation load, the more extended the volume of recrystallized material and the finer the recrystallized grain size. This result is linked to the fact that recrystallization temperature drops a few hundreds of degrees with increasing cold deformation; e.g., in the as-extruded PM2000, the recrystallization temperature recorded was $1330{ }^{\circ} \mathrm{C}$, but this temperature drops to $750{ }^{\circ} \mathrm{C}$ after a $47 \%$ reduction in area [40].

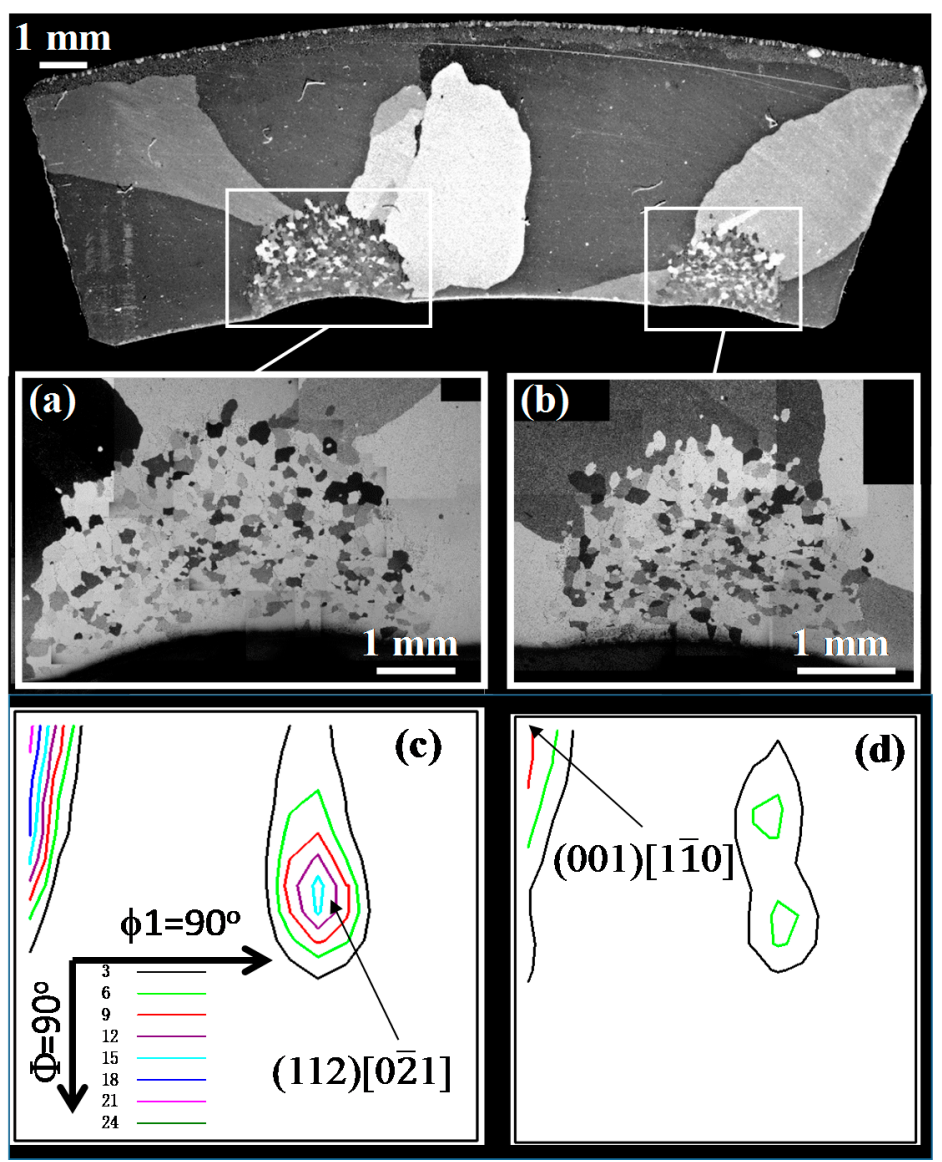

Figure 3. Recrystallized microstructure after annealing at $1350{ }^{\circ} \mathrm{C}$ for $3 \mathrm{~h}$ of the prior Brinell test areas with loads of (a) $49 \mathrm{kN}$, and (b) $29.5 \mathrm{kN}$, and the corresponding texture before recrystallization in (c) the indented and (d) non-indented areas.

However, the decrease in recrystallization temperature and the refinement of the microstructure deserves some discussion in this paper. The work reported by Toda et al. [26] demonstrates by finite element modeling that the side regions of the Brinell deformation print where recrystallization starts correspond to those regions where shear residual stresses reach the highest magnitude. Thus, it might be argued that residual shear stress triggers the nucleation of recrystallization, as described by Hutchinson and Wayne [41], and the recrystallized grains grow in the deformed area (where the stored energy is higher) but not into the surrounding non-deformed area.

On the other hand, an alternative explanation could be drawn on the basis of a texture change induced by cold deformation. Chou and Bhadeshia [32] measured the stored energies in the samples 
subjected to cold deformation after consolidation in an ODS steel similar to PM2000, and noticed no increase in stored energy with deformation; indeed, it turns out that cold deformation leads to a reduction in stored energy. It is conceivable that cold deformation modifies the crystallographic texture, thereby reducing the stored energy, and at the same time, causing a reduction in the recrystallization temperature. Texture could, for example, lead to the appearance of new orientations. This would weaken the strong as-extruded incomplete $\alpha$-fiber texture, avoiding the orientation pinning effect, thereby making the nucleation of recrystallization easier.

In this sense, published data on the correlation between crystallographic texture and recrystallization indicate that, when the cold-deformed texture is random, certain texture components grow at the expense of others in the course of recrystallization [42]. This process is similar to directional solidification, in which the fastest growing orientations are selected preferentially in the final microstructure. It is found that, during recrystallization of cold-deformed ferritic steels, the $\{111\}$ texture component grows preferentially [43], and a reasonable explanation for this could be that the boundary mobility of grains contributing to this particular component is relatively high. Hence, it follows that, at a given value of stored energy, a sample with a stronger $\{111\}$ texture should recrystallize more readily.

This result is consistent with texture measurements obtained by EBSD in the Brinell-deformed samples and shown in Figure 3. Figure 3d illustrates the non-indented region before recrystallization, and it presents a strong incomplete $\alpha$-fiber texture $(<110>\|$ RD and $<100>\| \mathrm{ND})$ with a dominating rotated cube $\{001\}<110>$ and a secondary $\{112\}$ weak component. On the contrary, the side regions of the Brinell deformation print present a significantly stronger $\{112\}<021>$ component before recrystallization (Figure 3c), which indicates a higher amount of $\{112\}$ grains as compared to the non-deformed state. That is, once the uniformity in the texture characteristic of as-extruded PM2000 is broken, the orientation pinning phenomenon that induces the stagnation of recrystallization is overcome, and the recrystallization temperature drops.

\subsection{Role of Extensive Directional Plastic Deformation in Recrystallization}

So far, we have discussed the role that slight deformations have in recrystallization of PM2000 by means of introducing heterogeneity in texture that overcomes the orientation pinning effect. The recrystallization temperature drops, and a significant grain refinement is achieved. It would be interesting, moreover, to discover a deformation path in such a way that the resulting deformation texture boosts the recrystallization of the microstructure into fine grains with a desirable texture. Hence, the design of a-la-carte ODS steels would be achieved.

Bearing this in mind, compression tests with elevated ratios of reduction in area are performed, both in parallel and transverse to the extrusion direction of PM2000 tube.

Figure 4 shows the IPF (Inverse Pole Figure) maps of as-extruded sample (Figure 4a) and L-sample and N-sample, both with an $80 \%$ reduction, i.e., L80 and N80 (Figure $4 \mathrm{~b}$ ). It is noted that there is a big difference in the IPF maps between the as-extruded and L80 and N80 samples as a consequence of the enormous forces that take part in this high level of compression. Although the material is forced to flow in the transverse direction of the applied load, the grains of the resulting microstructure are well delimited by HAGB. Bearing in mind the different scale bars in the figure, the resulting grain size is not very different for either the L80 or N80 samples, although there is a more elongated grain for the L80 sample. On the contrary, the deformed grains of the N80 sample present a more equiaxed morphology with a wavy shape characteristic of compression samples. The density, however, of LAGBs increases considerably as compared with the as-extruded state for both the L80 and N80 samples. This is more pronounced for the N80 sample. 

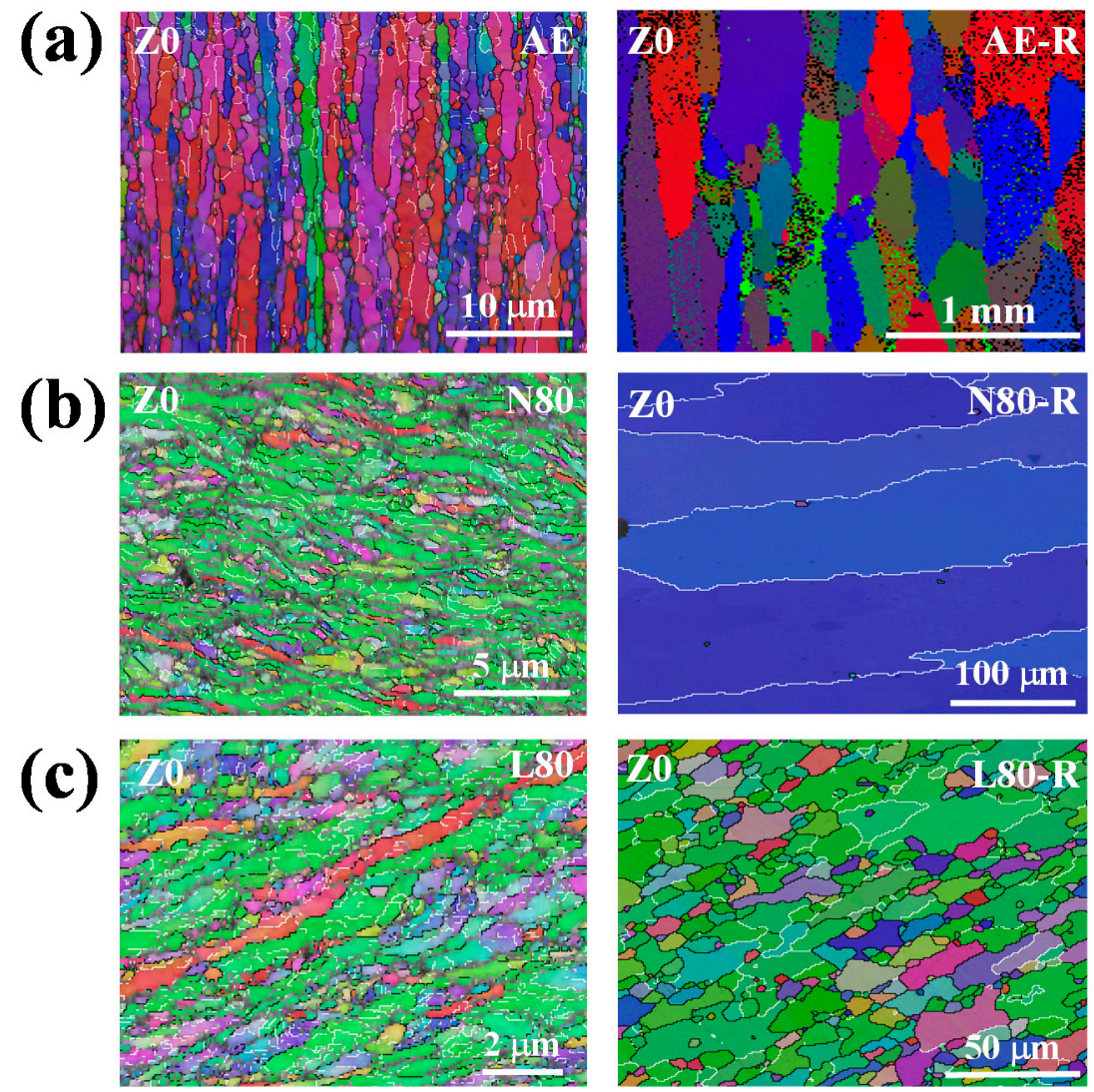

Figure 4. OIM map in Z0-axis for (a) as-extruded, (b) N-Sample with $80 \%$ compression ratio, and (c) L-sample with $80 \%$ compression ratio. Before (AE, L80 and N80, respectively) and after recrystallization (AE-R, L80-R and N80-R, respectively).

Nevertheless, radically different behaviors are observed (Figure 4c) with regard to the recrystallized microstructure. While a coarse-grained microstructure is obtained for the N80 sample, a fine quasi-equiaxic grain microstructure is observed for the L80 sample. The reason for such behavior cannot be derived from the IPFs maps shown in Figure 4. A close observation of the differences in deformation texture is required.

Figure 5, on the other hand, shows the ODF figures for both the L80 (Figure 5a) and N80 (Figure $5 \mathrm{~b}$ ) samples. The texture formed in the L80 sample is an intense $\gamma$-fiber, as shown in Figure 5a. The appearance of orientation pinning phenomenon is not likely to occur due to the high misorientation between neighboring grains. On the contrary, the ODF figure corresponding to the N80 sample (Figure $5 b$ ) shows a strongly rotated cube texture. In this case, there is a low misorientation between neighboring grains, and hence, the orientation pinning effect will promote the stagnation of recrystallization, jeopardizing the growth of recrystallized grains. This is consistent with the observed recrystallized microstructure formed by only a few coarse grains with a different texture from the deformed grains, but with low misorientations. 


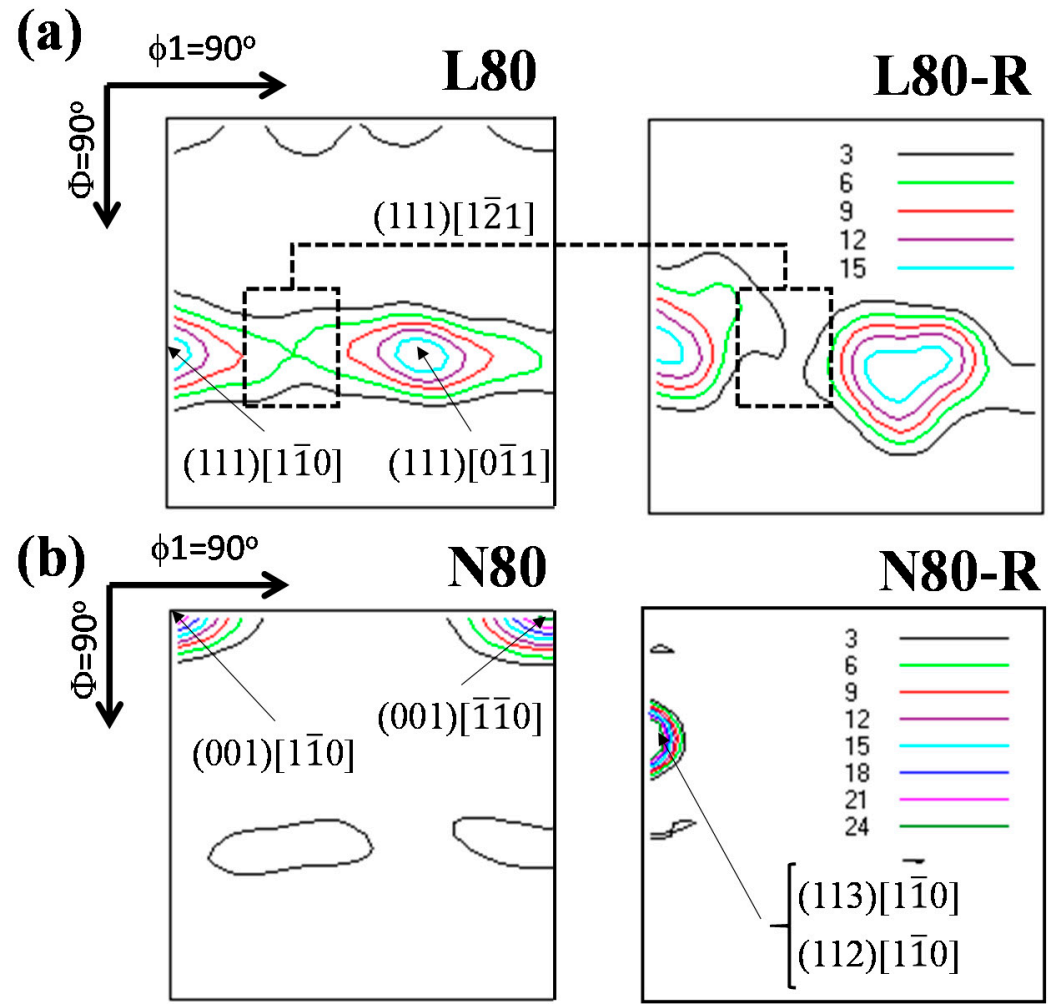

Figure 5. $\phi_{2}=45^{\circ}$ section of ODF for (a) L-Sample with $80 \%$ compression ratio, and (b) N-sample with $80 \%$ compression ratio. Before (L80 and N80, respectively) and after recrystallization (L80-R and $\mathrm{N} 80-\mathrm{R}$, respectively). The major texture components are indicated.

In addition, the comparison between deformed and recrystallized microstructures observed in Figure 5a allow us to conclude that there is a reinforcement of the (111)[110] component to the detriment of (111)[112]. This could be explained on the basis that the recrystallization process in PM2000 is an extended recovery processes driven by subgrain rotation, which is the result of the competition between neighboring subgrains for reducing the total system energy. The stored energy of the (111)[112] grains is higher than that of (111)[110], and hence, low-energy grains will tend to remain in the microstructure to the detriment of high-energy grains.

On the other hand, the stored energy of deformation in the N80 sample is mainly in the form of LAGBs, which are rather stable, and remains available for orientation pinning. These facts jeopardize the migration of HAGBs, promoting a recrystallized microstructure formed by a few coarse grains.

\section{Conclusions}

The recrystallization mechanism in PM2000 is actually an extended recovery process consisting of a geometrical change in grain morphology, no nucleation stage, an increase in percentage of LAGBs, and no significant change in material texture. There is, however, a strengthening in the texture component towards the $\{001\}<110>$ (lower Taylor factor) due to subgrain rotation.

The effect of cold deformation on the recrystallization of PM2000 samples is twofold. Firstly, the recrystallization temperature decreases, consistent with the hypothesis that anything that makes the original microstructure heterogeneous will encourage recrystallization. This is because the microstructure prior to recrystallization is uniform, with grains that are so fine that their junctions are powerful pinning points. In addition to that, the stagnation of recrystallization is substantially triggered by the absence of $\gamma$-fiber components in the deformed microstructure. The uniform microstructure prior to recrystallization is strengthened by the increase of LAGBs due to subgrain rotation driven by dislocation glide. This promotes the orientation pinning mechanism of HAGBs. The increase in 
misorientation between neighboring grains due to cold deformation weakens the orientation pinning, triggering the recrystallization.

The second effect that cold deformation has on recrystallization is related with the change in crystallographic texture. In the particular case of PM2000, the increase of $\{111\}$ grains with cold deformation will prone the nucleation of recrystallization. This is fully consistent with the results obtained after recrystallization of directional strongly deformed L-samples, where an intense $\gamma$-fiber is built in detriment of the as-extruded texture, prior to cold deformation, consisting of an incomplete intense $\alpha$-fiber texture $(<110>\|$ RD and $<100>\| N D)$ with a dominating rotated cube $\{001\}<110>$ component.

Author Contributions: All authors were involved in the results discussion and in finalizing the manuscript.

Funding: The authors acknowledge financial support from the Spanish Ministerio de Economia y Competitividad (MINECO) in the form of a Coordinate Project (MAT2016-80875-C3-1-R).

Acknowledgments: The work presented here is done within the Joint Programme on Nuclear Materials of the European Energy Research Alliance Pilot Project CREMAR. The authors would also like to acknowledge financial support from Comunidad de Madrid through DIMMAT-CM_S2013/MIT-2775 project. J. Vivas acknowledges financial support in the form of a FPI Grant BES-2014-069863.

Conflicts of Interest: The authors declare no conflict of interest.

\section{References}

1. Benjamin, J.S. Dispersion strengthened superalloys by mechanical alloying. Metall. Trans. 1970, 1, 2943-2951.

2. Ukai, S.; Ohtsuka, S.; Kaito, T.; de Carlan, Y.; Ribis, J.; Malaplate, J. Oxide Dispersion-Strengthened/ Ferrite-Martensite Steels as Core Materials for Generation IV Nuclear Reactors. In Structural Materials for Generation IV Nuclear Reactors; Woodhead Publishing: Cambridge, UK, 2016; pp. 357-414.

3. Evens, P.J.; Martin, J.W.; Little, E.A. Secondary recrystallisation of MA 957 oxide dispersion strengthened ferritic superalloy. Mater. Sci. Technol. 1992, 8, 531-536. [CrossRef]

4. Chen, Y.L.; Jones, A.R. The microstructure and recrystallization of flow-formed oxide-dispersionstrengthened ferritic alloy: Part I. Deformation structure. Metall. Mater. Trans. A 2002, 33, 3777-3785. [CrossRef]

5. Hack, G.A.J. Developments in the production of oxide dispersion strengthened superalloys. Powder Metall. 1984, 27, 73-79. [CrossRef]

6. Singer, R.F.; Gessinger, G.H. Hot isostatic pressing of oxide dispersion strengthened superalloy parts. Powder Metall. Int. 1983, 15, 119-121.

7. Baloch, M.M.; Bhadeshia, H.K.D.H. Directional recrystallisation in Inconel MA 6000 nickel base oxide dispersion strengthened superalloy. Mater. Sci. Technol. 1990, 6, 1236-1246. [CrossRef]

8. Jones, A.R.; Ritherdon, J. Reduction in defect content of oxide dispersion strengthened alloys. Mater. High Temp. 1999, 16, 181-188. [CrossRef]

9. Jongenburger, C.P.; Singer, R.F. Recrystallization of ODS Superalloys; Dgm 384 Metallurgy Information: New York, NY, USA, 1989; pp. 157-174.

10. Regle, H.; Alamo, A. Secondary recrystallization of oxide dispersion strengthened ferritic alloys. J. Phys. IV 1993, 3, 727-730. [CrossRef]

11. Chou, T.S.; Bhadeshia, H. Grain control in mechanically alloyed oxide dispersion-strengthened MA-957 STEEL. Mater. Sci. Technol. 1993, 9, 890-897. [CrossRef]

12. Murakami, K.; Mino, K.; Harada, H.; Bhadeshia, H. Nonuniform recrystallization in a mechanically alloyed nickel-base superalloy. Metall. Trans. A 1993, 24, 1049-1055. [CrossRef]

13. Pimentel, G.; Toda-Caraballo, I.; Chao, J.; Capdevila, C. Role of strain heterogeneity on recrystallisation of oxide dispersion strengthened $\mathrm{Fe}-\mathrm{Cr}-\mathrm{Al}$ alloys for high-temperature applications. Asian J. Mater. Sci. 2012, 47, 5605-5616. [CrossRef]

14. Capdevila, C.; Chen, Y.L.; Lassen, N.C.K.; Jones, A.R.; Bhadeshia, H. Heterogeneous deformation and recrystallisation of iron base oxide dispersion strengthened PM2000 alloy. Mater. Sci. Technol. 2001, 17, 693-699. [CrossRef] 
15. Capdevila, C.; Chen, Y.L.; Jones, A.R.; Bhadeshia, H. Grain boundary mobility in Fe-base oxide dispersion strengthened PM2000 alloy. ISIJ Int. 2003, 43, 777-783. [CrossRef]

16. Chao, J.; Capdevila, C.; Serrano, M.; Garcia-Junceda, A.; Jimenez, J.A.; Pimentel, G.; Urones-Garrote, E. Notch impact behavior of oxide-dispersion-strengthened (ODS) Fe20Cr5Al alloy. Metall. Mater. Trans. A 2013, 44, 4581-4594. [CrossRef]

17. Pimentel, G.; Chao, J.; Capdevila, C. Recrystallization process in Fe-Cr-Al oxide dispersion-strengthened alloy: Microstructural evolution and recrystallization mechanism. JOM 2014, 66, 780-792. [CrossRef]

18. Bhadeshia, H. Recrystallisation of practical mechanically alloyed iron-base and nickel-base superalloys. Mater. Sci. Eng. A 1997, 223, 64-77. [CrossRef]

19. Capdevila, C.; Bhadeshia, H. Manufacturing and microstructural evolution of mechanuically alloyed oxide dispersion strengthened superalloys. Adv. Eng. Mater. 2001, 3, 647-656. [CrossRef]

20. Sha, W.; Bhadeshia, H.K.D.H. Modelling of recrystallisation in mechanically alloyed materials. Mater. Sci. Eng. A 1997, 223, 91-98. [CrossRef]

21. Sha, W.; Bhadeshia, H. Characterization of mechanically alloyed oxide dispersion-strengthened nickel-base superalloy MA760. Metall. Mater. Trans. A 1994, 25, 705-714. [CrossRef]

22. Murakami, K.; Mino, K.; Harada, H.; Bhadeshia, H. Discussion of the distribution of dispersoid phases in the extruded ODS superalloy MA-957. Metall. Mater. Trans. A 1994, 25, 652-653. [CrossRef]

23. Capdevila, C.; Miller, U.; Jelenak, H.; Bhadeshia, H. Strain heterogeneity and the production of coarse grains in mechanically alloyed iron-based PM2000 alloy. Mater. Sci. Eng. A 2001, 316, 161-165. [CrossRef]

24. Capdevila, C.; Bhadeshia, H.K.D.H. Program MAP_STEEL_ANREC. Available online: https://www.phasetrans.msm.cam.ac.uk/map/steel/programs/anrec.html (accessed on 6 November 2018).

25. Capdevila, C.; Bhadeshia, H.K.D.H. Program MAP_STEEL_TR. Available online: https://www.phase-trans. msm.cam.ac.uk/map/steel/programs/tr_model.html (accessed on 6 November 2018).

26. Toda-Caraballo, I.; Chao, J.; Lindgren, L.E.; Capdevila, C. Effect of residual stress on recrystallization behavior of mechanically alloyed steels. Scr. Mater. 2010, 62, 41-44. [CrossRef]

27. Dillamore, I.L.; Watson, T.W.; Hadden, P.; Hazel, R.J. An experimental study of the mechanical anisotropy of some common metals. Int. J. Mech. Sci. 1971, 13, 1049-1061. [CrossRef]

28. Every, R.L.; Hatherly, M. Oriented nucleation in low-carbon steels. Texture 1974, 1, 183-194. [CrossRef]

29. Doherty, R.D.; Hughes, D.A.; Humphreys, F.J.; Jonas, J.J.; Juul Jensen, D.; Kassner, M.E.; King, W.E.; McNelley, T.R.; McQueen, H.J.; Rollett, A.D. Current issues in recrystallization: A review. Mater. Sci. Eng. A 1997, 238, 219-274. [CrossRef]

30. Huh, M.Y.; Cho, Y.S.; Engler, O. Effect of lubrication on the evolution of microstructure and texture during rolling and recrystallization of copper. Mater. Sci. Eng. A 1998, 247, 152-164. [CrossRef]

31. Gudmundsson, H.; Brooks, D.; Wert, J.A. Mechanisms of continuous recrystallization in an Al-Zr-Si alloy. Acta Metall. Mater. 1991, 39, 19-35. [CrossRef]

32. Chou, T.S.; Bhadeshia, H. Crystallographic texture in mechanically alloyed oxide dispersion-strengthened MA956 AND MA957 STEELS. Metall. Trans. A 1993, 24, 773-779. [CrossRef]

33. Chou, T.S.; Bhadeshia, H. Dynamic recrystallisation in hot deformed oxide dispersion strengthened MA956 and MA957 steels. Mater. Sci. Technol. 1995, 11, 1129-1138. [CrossRef]

34. Lyttle, M.T.; Wert, J.A. Modelling of continuous recrystallization in aluminium alloys. Asian J. Mater. Sci. 1994, 29, 3342-3350. [CrossRef]

35. Juul Jensen, D. Growth rates and misorientation relationships between growing nuclei/grains and the surrounding deformed matrix during recrystallization. Acta Metall. Mater. 1995, 43, 4117-4129. [CrossRef]

36. Vandermeer, R.A.; Juul Jensen, D. Migration of high angle grain boundaries during recrystallization. Interface Sci. 1998, 6, 95-104. [CrossRef]

37. Alamo, A.; Regle, H.; Bechade, J.L. Effects of processing on textures and tensile properties of oxide dispersion strengthened ferritic alloys obtained by mechanical alloying. Adv. Powder. Metall. Part. Mater. 1992, 7 , 169-182.

38. Onel, K.; Nutting, J. Recrystallization and grain-growth in deformed and tempered carbon-steels. Metal Sci. 1981, 15, 89-94. [CrossRef]

39. Montes, C.C.; Bhadeshia, H. Influence of deformation on recrystallization of an yttrium oxide dispersion-strengthened iron alloy (PM2000). Adv. Eng. Mater. 2003, 5, 232-237. [CrossRef] 
40. Pimentel, G.; Aranda, M.M.; Chao, J.; González-Carrasco, J.L.; Capdevila, C. Development of simultaneous corrosion barrier and optimized microstructure in FeCrAl heat-resistant alloy for energy applications. Part II: The optimized creep-resistant microstructure. JOM 2015, 67, 2055-2061. [CrossRef]

41. Hutchinson, B.; Wynne, B. Effects of Stress on Structure Transformations in Metals. Mater. Sci. Forum 2007, 550, 149-158. [CrossRef]

42. Ur, S.C.; Nash, P.; Higgins, G.T. Grain growth and secondary recrystallization in mechanically alloyed NiAl. Scr. Mater. 1996, 34, 53-59. [CrossRef]

43. Hutchinson, B. Deformation microstructures and textures in steels. Philos. Trans. R. Soc. London Ser. A 1999, 357, 1471-1485. [CrossRef]

(C) 2018 by the authors. Licensee MDPI, Basel, Switzerland. This article is an open access article distributed under the terms and conditions of the Creative Commons Attribution (CC BY) license (http:/ / creativecommons.org/licenses/by/4.0/). 